medicine. 6, 64 - 69 .

6. Trinnh Văn Thảo (2010). Nghiên cứu ứng dụng phâu thuật nội soi đặt mảnh ghép hoàn toàn ngoài phúc mạc trong điều trị thoát vị bẹn. Luận án tiến sĩ. Học viên Quân Y.

7. Kockerling F., et al (2015). Bilateral and Unilateral Total Extraperitoneal Inguinal Hernia Repair (TEP) have Equivalent Early Outcomes: Analysis of 9395 Cases. World J Surg. 39(8), 1887-94.

8. Asuri Krishna, et al (2019). Totally Extraperitoneal Repair in Inguinal Hernia: More Than a Decade's Experience at a Tertiary Care Hospital. Surg Laparosc Endosc Percutan Tech. 29 $247-251$.

\title{
NGHIÊN CỨU ĐĂC ĐIỂM HÌNH ẢNH SIÊU ÂM NộI SOI U MỐ ĐỆM MẠC DẠ DÀY RUộT
}

\author{
Nguyễn Công Long ${ }^{1}$, Chử Quang $\mathrm{Huy}^{2}$, Vũ Trường Khanh ${ }^{1}$
}

\section{TÓM TẮT}

Muc tiêu: Đánh giá đăc điểm hình ảnh nội soi và siêu ẩm nội soi u mô đệm dạ dày ruột (GIST). Đối tượng và phương pháp: Bệnh nhân có u dưới niêm mạc dạ dày được đánh giá đặc điểm hình ảnh bằng siểu âm nội soi (EUS). Tất cả u được chẩn đoán xác định bằng mô bệnh học là GIST qua sinh thiết dưới hướng dẫn của siêu âm nội soi hoặc phẫu thuật. Kết quả: 28 bênh nhân có $28 \mathrm{u}$, với 10 nam và 18 nữ được đưa vào nghiên cứu. Kích thước trung bình của u là $3,94 \pm 0,73 \mathrm{~cm}$ (từ 1,8 đến $6,2 \mathrm{~cm}$ ). Vị trí u nằm ở lớp cơ là $75 \%$, dưới niêm mạc $21,4 \%$ và lớp cơ niêm là 3,6\% các trường hợp. Tính chất âm trên siêu âm nội soi, u giảm âm chiếm $14(50 \%)$ bệnh nhân, $13(46,4 \%)$ bệnh nhân là khối hỗn hợp âm, 1(3,6\%) trường hợp tắng âm. Kết luận: Tỷ lệ u GIST gặp cao nhất nằm ở lớp cơ của ống tiêu hóa, với tính chất giảm âm và hốn hợp âm. nội soi

Từ khoá: U mồ đệm dạ dày ruột, dạ dày, siêu âm

\section{SUMMARY}

ENDOSCOPIC ULTRASONOGRAPHIC CHARACTERISTICS OF GASTRIC GASTROINTESTINAL STROMA TUMOR

Objective: To identify imaging characteristics of endoscopic and endoscopic ultrasonography for the diagnosis of gastrointestinal stromal tumors (GIST) in gastric. Subjects and methods: Patients who had gastric stromal tumors diagnosed by Endoscopic ultrasound-guided fine needle aspiration (EUS-FNA) or surgery were enrolled. The EUS images, procedure records and tissue histopathology were reviewed. All patients were positive for C-kit, CD34. Results: Of the 28 patients enrolled, 10 were males, and 18 were females. The mean size of lesion was $3.94 \pm 0.73 \mathrm{~cm}$ (ranged from 1.8 to $6.2 \mathrm{~cm}$ ). In total, $75 \%, 21.4 \%$, and $3.6 \%$ tumors originated from muscularis mucosa submucosa, and muscularis propria, respectively. $50 \%$

1 Trung tâm tiêu hóa gan mật bệnh viện Bạch mai 2Bênh viên phổi trung ương

Chịu trách nhiệm chính: Nguyễn Công Long

Email: nguyenconglongbvbm@gmail.com

Ngày nhận bài: 13.5.2021

Ngày phản biên khoa hoc: 6.7.2021

Ngày duyệt bài: 14.7.2021 and $46.4 \%$ of these lesions were characterized by hypoechoic, heterogeneous respectively. Conclusion: The preliminary results show that most of the GISTs originated from muscularis mucosa with characterized by hypoechoic.

Key words: GIST, gastric, endoscopic ultrasonography

\section{I. ĐĂTT VẤN ĐỀ}

Các u dưới niêm mạc dạ dày (Gastric Submucosal Tumor - GSMT ) hay còn gọi là các u dạ dày không biểu mô vì các u có nguôn gốc từ tổ chức liên kết và thường được chẩn đoán dựa vào nội soi da dày. Các GSMT hay gặp nhất trong nội soi đường tiêu hóa trên là các u mô đệm dạ dày - ruột (Gastrointestinal Stromal Tumors - GISTs). Các khối u GIST dạ dày chiếm khoảng 40- 60\% của tất cả các u GIST đường tiêu hóa $[1,2]$. Những khối u này có thể được chẩn đoán là u cơ trớn hay u thân kinh (Schwannoma) [2] vì có sự tương đồng về mô học. Ngoài ra u dưới niêm mạc còn được phân thành nhiêu nhóm như u cớ trơn, u tế bào Shwann, u lympho nguyên phát không Hodgkin dạ dày, u xơ thân kinh, u xơ, u mõ̃, các u mạch. Việc chẩn đoán u dưới niêm mạc dạ dày thường được phát hiện tình cờ khi nội soi đường tiêu hóa trên vì các triệu chứng lâm sàng thường không điển hình, u phát triển âm thầm ở dưới niêm mạc, bề mă̆t niêm mạc bình thường hoặc có tổn thương, nhưng thường không có hình ảnh đăc trưng mà chỉ quan sát thây hình ảnh khối đẩy lî̀i vào lòng dạ dày. Việc sinh thiết để chẩn đoán mô bệnh được chính xác u cũng khó khăn do u nằm dưới niểm mạc dẫn đến thường được phát hiện và chẩn đoán muộn sau nhiêu năm. Sự phát triển của kỹ thuật siêu âm nội soi đường tiểu hóa trên (Endoscopic Ultrasonography - EUS) [3] giúp ích rất nhiều cho việc chẩn đoán xác định lớp và có thể tiến hành chọc hút dưới kim nhỏ chính xác vị trí khối u [4]. Tuy nhiên tại Việt Nam ít có công trình nào đánh giá về nghiên cứu đặc 
điểm hình ảnh nội soi và EUS của u mô đêm da dày. Nên chúng tôi tiến hành nghiên cứu đặc điểm hình ảnh nội soi và siêu âm nội soi của u mô đệm dạ dày.

\section{II. ĐỐI TƯợNG VÀ PHƯƠNG PHÁP NGHIÊN CỨU}

Đối tượng: Nghiên cứu 28 bệnh nhân được làm nội soi thấy có tổn thương u dưới niêm mạc, sau đó bệnh nhân được làm siêu âm nội soi mô tả vị trí lớp khối $u$, kích thước khối $u$, tính chất âm và được chẩn đoán xác định lại bằng mô bệnh học sau khi đã được phẫu thuật hoặc chọc hút là GIST tại bệnh viện Bạch mai từ năm 2015 đến năm 2017.

Phương pháp: Bệnh nhân có hình ảnh tổn thương u dưới niêm mạc của dạ dày qua siêu âm nội soi tại khoa tiêu hóa bệnh viện Bạch mai. Bệnh nhẩn được khám lâm sàng và được chỉ định phẫu thuật hoặc chọc hút để làm xét nghiệm mô bệnh học và có nhuộm hóa mô C-kit, CD34. Để đánh giá mức độ tượng ứng trên hình ảnh siêu âm nội soi và nội soi thường ở các bênh nhân u mô đệm dạ dày. Tiêu chuẩn chọn bệnh nhân được làm siểu âm nội soi tại bệnh viện Bạch Mai và thây tổ chức u dưới niêm mạc sau đó bệnh nhân được theo dõi cho đến khi bệnh nhân được phẫu thuật và có kết quả giải phẫu mô bệnh học được làm tại trung tâm giải phẫu bệnh Bệnh viện Bạch Mai kết luận là GIST.

Xử lý số liệu: Sau khi thu thập đầy đủ các số liệu, quá trình xử lý được làm trên máy tính với phần mềm xử lý số liệu SPSS 20, giá trị $\mathrm{P}<$ 0,05 được xác định là mức khác biệt có ý nghĩa thống kề.

\section{KẾT QUẢ NGHIÊN CỨU}

Nghiên cứu 28 bệnh nhân với 28 u dưới niêm mạc dạ dày được chẩn đoán bằng siêu âm nội soi và được chẩn đoán xác định lại bằng mô bệnh học là GIST (trong đó 24 bệnh nhân được phẫu thuật và 4 bênh nhân chẩn đoán bằng chọc hút dưới hướng dẫn siêu âm nội soi). Trên hình ảnh nội soi vị trí vị trí phình vị $5(17,9 \%)$, thân vị $18(64,3 \%)$ và hang vị 5 (17,9\%) bệnh nhân. Tổn thương quan sát trên nội soi bề mặt niêm mạc u trên 28 bênh nhân cho thấy hầu hết trường hợp thấy niểm mạc bình thường $21(75 \%)$ bệnh nhân , 5(17,9\%) bệnh nhân thấy hình ảnh loét trên bề mặt, $2(7,1 \%)$ bệnh nhân thây hình ảnh loét chảy máu ổ loét.

Bảng 1. Kích thước và vị trí U GIST qua siêu âm nôi soi

Kích thước khối U $\quad$ Vị trí khối u

n(\%) $\quad$ n(\%)

\begin{tabular}{|c|c|c|c|}
\hline$\leq 2 \mathrm{~cm}$ & $3(10,7 \%)$ & Lớp cơ & $21(75 \%)$ \\
\hline $2-3 \mathrm{~cm}$ & $8(28,6 \%)$ & $\begin{array}{c}\text { Lớp dưới } \\
\text { niêm mạc }\end{array}$ & $6(21,4 \%)$ \\
\hline $3-5 \mathrm{~cm}$ & $11(39,3 \%)$ & $\begin{array}{c}\text { Lớp cớ } \\
\text { niêm }\end{array}$ & $1(3,6 \%)$ \\
\hline$\geq 5 \mathrm{~cm}$ & $6(21,4 \%)$ & & \\
\hline $\begin{array}{l}\text { Kích thước } \\
\text { trung bình }\end{array}$ & $\begin{array}{c}3,94 \pm 0,73 \\
(1,8-6,2)\end{array}$ & & \\
\hline
\end{tabular}

Trong nghiên cứu của chúng tôi, kích thước u GIST qua siêu âm nội soi từ $3-5 \mathrm{~cm}$ chiếm tỉ lệ cao nhất 39,3\%, tiếp đó là khối u kích thước 2$3 \mathrm{~cm}$ chiếm $8(28,6 \%)$ trường hợp và phát hiện 6 $(21,4 \%)$ trường hợp có kích thước trên $5 \mathrm{~cm}$ (Bảng 1). Vị trí các khối GIST tập trung chủ yếu ở lớp cơ dạ dày $(75 \%)$ và lớp dưới niêm mạc $(21,4 \%)$, chỉ có $1(3,57 \%)$ trường hợp thây khối u ở lớp cơ niêm.

Bảng 2. Tính chất khôi U GIST qua siêu âm nội soi

\begin{tabular}{|c|c|c|c|}
\hline \multicolumn{2}{|c|}{$\begin{array}{c}\text { Tính chất âm } \\
\text { khối U }\end{array}$} & \multicolumn{2}{|c|}{$\begin{array}{c}\text { Tính chất ranh } \\
\text { giới khôi U }\end{array}$} \\
\hline & $\mathbf{n ( \% )}$ & \multicolumn{1}{|c|}{$\mathbf{n ( \% )}$} \\
\hline $\begin{array}{c}\text { Giảm } \\
\text { âm }\end{array}$ & $14(50 \%)$ & Ranh giới rõ & $21(75 \%))$ \\
\hline $\begin{array}{c}\text { Tăng } \\
\text { âm }\end{array}$ & $1(3,6 \%)$ & $\begin{array}{c}\text { Ranh giới } \\
\text { không rõ }\end{array}$ & $6(21,4 \%)$ \\
\hline $\begin{array}{c}\text { Hô̂n } \\
\text { hợp âm }\end{array}$ & $\begin{array}{c}13 \\
(46,4 \%)\end{array}$ & $\begin{array}{c}\text { Hình ảnh canxi trong } \\
\text { khối U }\end{array}$ \\
\hline & & $\begin{array}{c}\text { Có hình ảnh } \\
\text { canxi }\end{array}$ & $9(32,1 \%)$ \\
\hline & & $\begin{array}{c}\text { Không có hình } \\
\text { ảnh canxi }\end{array}$ & $19(67,9 \%)$ \\
\hline
\end{tabular}

Đa số các trường hợp GIST có bờ rõ nét chiếm 21(75\%) trường hợp. Đặc điểm hình ảnh trên siêu âm nội soi của khối GIST thấy tỉ lệ khối giảm âm chiếm một nửa với $14(50 \%)$ trường hợp. 9(32,1\%) trường hợp có hình ảnh nốt canxi hóa trong khối u (Bảng 2).

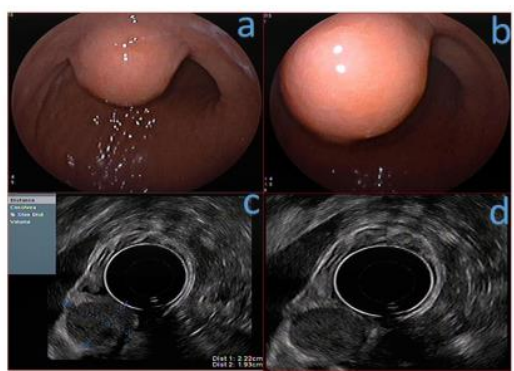

Hình 1. Hình ảnh minh họ a) Hinh ảnh nội soi u dươi niêm mạc da dày nhin xa. b) Hình ảnh bề mặt niêm mạc khối u binh thường; c) đo kích thước khối u trên siêu âm nội soi; d) khối u xuât phát từ lớp cơ thành dạ dày. 


\section{BÀN LUÂN}

U mô đệm dạ dày ruột (GIST) là loại u trung mô thường gặp nhất ở dạ dày và có nguy cơ ác tính $[5,6]$. Nguồn gốc GIST xuất phát từ các tế bào kẽ Cajal và để chẩn đoán xác định qua nhuộm hóa mô CD34, CD 117, và protein c-kit. Nguy cơ ác tính của GIST rất khác nhau nó phụ thuộc vào hai yếu tố là kích thước khối u và tốc độ phân bào.

Hình ảnh trên nôi soi của u GIST điển hình là các tổn thương dạng u dưới niêm mạc có hình Iõm ở giữa. Trong nghiên cứu của chúng tôi ở 28 bệnh nhân, trên hình ảnh nội soi dạ dày thì đều là khối u dạng dưới niêm mạc, với $75 \%$ trường hợp có niêm mạc bề mặt bình thường, 17,9\% bệnh nhân có loét bề mặt $u, 7,1 \%$ trường hợp có loét đang chảy máu. Một số nghiên cứu khác cũng cho thấy tỷ lệ gặp loét bề mặt niêm mạc ở u GIST dạ dày tới 48\% [7]. Vị trí khối u tỷ lệ gặp tại hang vị có $5(17,9 \%)$ bệnh nhân, $5(17,9 \%)$ bệnh nhân có khối u ở phình vị và $18(64,3 \%)$ bểnh nhân có u tai thân vị. Hình ảnh siêu âm nôi soi điển hình là khối giảm âm, thường xuất phát từ lớp 2 (lớp cơ niêm) hoặc lớp 4 (lớp cơ của thành dạ dày). Như ảnh minh họa (Hình 1) một bênh nhân trong nghiên cứu của chúng tôi thì khối u xuất phát từ lớp cơ của thành dạ dày, khối u có tính chất giảm âm và tương đối đồng nhất đây là hình ảnh điển hình của u GIST da dày trên siêu âm nội soi. Kết quả nghiên cứu của chúng tôi cũng ghi nhận tới $75 \%$ khối u xuất phát từ lớp cơ của thành da dày và chỉ có 6 trường hợp chiếm $21,4 \%$ xuất phát từ lớp dưới niêm mạc da dày. EUS có thể cho phép ta đo được kích thước khối u. Trong nghiên cứu của chúng tôi kích thước khối u từ 3-5 cm chiếm tỉ lệ cao nhất $11(39,3 \%)$, tiếp đó là khối u kích thước $2-3 \mathrm{~cm}$ chiếm $8(28,6 \%)$ trường hợp và phát hiện $6(21,4 \%)$ trường hợp có kích thước trên $5 \mathrm{~cm}$. Kích thước trung bình khối u là 3,94 $\pm 0,73 \mathrm{~cm}$. Đặc điểm bờ khối u, cấu trúc trong khối u như nang trong khối u, hình ảnh khối trong khối, hoặc hình ảnh hạch bao quanh khối có hay khổng, các đặc điểm đó đều mang tính chất có thể gợi ý tính chất ác tính của u [8,9]. Trong nghiên cứu của chúng tôi cho thấy tính chất khối u GIST thường có ranh giới rõ chiếm $75 \%$ các trường hợp, và $50 \%$ các trường hợp có tính chất giảm âm. Mặc dù có thể đưa ra nhiều thông số dựa trên EUS nhưng với các khối u kích thước nhỏ cần phải chẩn đoán phân biệt với các loại u khác, nhiêu khi chúng ta phải theo dõi theo thời gian về kích thước khối u. Tuy nhiên ở nghiên cứu chúng tôi tiến hành sinh thiết khối u dưới hướng dẫn của siêu âm nội soi để có chẩn đoán mô bệnh học, khi bệnh nhân có kích thước khối u lớn bệnh nhân được khuyến cáo phẫu thuật và bệnh nhân được khẳng định sau mổ là u GIST dạ dày.

\section{KẾT LUẬN}

Trong nghiên cứu của chúng tôi siêu âm nội soi giúp làm tăng tỉ lệ chẩn đoán u mô đệm dạ dày so với nội soi thường, giúp đánh giá tiên lượng mức độ nguy cơ của các khối u qua việc biểt vị trí lớp, tính chất âm của khối u, đánh giá chính xác hơn kích thước, cũng như đánh giá mức độ xâm lấn và các hạch xung quanh để có chỉ định phẫu thuật phù hợp.

\section{TÀI LIÊU THAM KHẢO}

1. Miettinen $M$, Sobin LH, Lasota J: Gastrointestinal stromal tumors of the stomach: a clinicopathologic, immunohistochemical, and molecular genetic study of 1765 cases with longterm follow-up. The American journal of surgical pathology 2005, 29(1):52-68.

2. Hwang JH, Rulyak SD, Kimmey MB: American Gastroenterological Association Institute technical review on the management of gastric subepithelial masses. Gastroenterology 2006, 130(7):2217-2228.

3. Sepe PS, Brugge WR: A guide for the diagnosis and management of gastrointestinal stromal cell tumors. Nature reviews Gastroenterology \& hepatology 2009, 6(6):363-371.

4. Akahoshi $K$, Sumida $Y$, Matsui $N$, Oya $M$, Akinaga $\mathbf{R}$, Kubokawa $M$, Motomura $\mathbf{Y}$, Honda K, Watanabe M, Nagaie T: Preoperative diagnosis of gastrointestinal stromal tumor by endoscopic ultrasound-guided fine needle aspiration. World J Gastroenterol 2007, 13(14):2077-2082.

5. Di Vita $M$, Zanghì $A$, Cavallaro $A$, Cardì $F$, Uhlig M, Ursi P, Lo Menzo E, Panebianco V', Cappellani A: Gastric GIST and prognostic models. Which is the best to predict survival after surgery? Annali italiani di chirurgia 2019, 90:31-40.

6. Miettinen $M$, Sarlomo-Rikala $M$, Lasota J: Gastrointestinal stromal tumors: recent advances in understanding of their biology. Human pathology 1999, 30(10):1213-1220.

7. Martínez-Ares $D$, Souto-Ruzo J, Yáñez López J, Vázquez Iglesias JL: Usefulness of endoscopic ultrasonography in the preoperative diagnosis of submucosal digestive tumours. Revista espanola de enfermedades digestivas : organo oficial de la Sociedad Espanola de Patologia Digestiva 2005, 97(6):416-426.

8. Palazzo L, Landi B, Cellier C, Cuillerier E, Roseau G, Barbier JP: Endosonographic features predictive of benign and malignant gastrointestinal stromal cell tumours. Gut 2000, 46(1):88-92.

9. Shah P, Gao F, Edmundowicz SA, Azar RR, Early DS: Predicting malignant potential of gastrointestinal stromal tumors using endoscopic ultrasound. Digestive diseases and sciences 2009, 54(6):1265-1269. 